\title{
Maximum Solar Power Generation through Optimization of Tilt Solar Angles of Solar Panels by Heuristic Technique
}

\author{
T.Som ${ }^{1}$, R.Pathak ${ }^{2}$ \\ Assistant Professor, Department of Electrical \&Electronics, JSSATEN, UPTU University, India ${ }^{1}$ \\ Assistant Professor, Department of Electrical \& Electronics, NIEC, IP University, New Delhi, India ${ }^{2}$
}

\begin{abstract}
The optimal power generation from a solar power system for a detailed loading and irradiation scenario prevailing at a specific location in India has been determined. Three different types of loads reflecting economic and residential activity at the location has been considered. Daily global and diffuse solar irradiation data corresponding to two different seasons of the year have been used in the radiation model for the solar panel. The optimal operation is being determined through optimal choice of the tilt angle for the solar panel in order to collect the most concentrated solar irradiation. The mathematical technique used is a modified version of the conventional genetic algorithm (GA) termed Tuned Genetic Algorithm (TGA). TGA is robust against the above discussed variations by virtue of metaheuristic nature and is more reliable in avoiding a local minimum of the objective function than GA. The TGAevaluated total solar power generations for each loading system in India utilizing different values of tilt angles of solar panel have been compared. The solar power generation is found to exceed demand by the largest margins for all three loads in summer season during optimal power operation. For most economic operation of the solar power system during the summer season, a 60 degree angle of tilt was found to be optimal for residential loads, whereas 50 degree tilt angle was optimal for the other loads studied.
\end{abstract}

Keywords: Solar Angle,Irradiation, TGA, Optimal Power.

\section{INTRODUCTION}

World electricity generation is going to touch 39 trillion $\mathrm{kWh}$ by the year 2040 which is almost a $100 \%$ jump from total generation of 20.2 trillion $\mathrm{kWh}$ in year 2010[1]. This very perpetual demand of energy, depleting stock of fuels, increase in fuel prices, environment concerns have called upon all stake holders to depart from convention way of energy generation and distribution. The new energy paradigm must have attributes of decentralization, diversification on fuels, environment friendliness and integration of DERs at its core for its sustainability in future [2-3]. Solar power is poised to occupy centre stage, as the chief contributor for energy security. The insolation received from sun in one hour is more than the energy consumed by all human population in one year [4]

In context of India, all condition seems to favours large scale exploitation of solar power. Despite of India being world fifth largest electrical power generator installation capacity of 243028.95MW as on March 2014[5], there is power deficit. Secondly, geographical location of India ensures that India receive solar energy equivalent of more than 5000 trillion $\mathrm{kWh} /$ year [6] average intensity of solar radiation remains at an average value of $200 \mathrm{MW} / \mathrm{km}^{2}$. With $58 \%$ of land area receiving annual average Global insolation above $5 \mathrm{kWh} / \mathrm{m}^{2} /$ day, having no of sunny days 250 to 325 over an year, India is standing at dawn of solar revolution [7-8].

Currently two approaches are being employed to generate electricity from solar energy, namely solar thermal and photovoltaic (PV). PV system which directly converts solar power in electricity with photoelectric effect are preferable for local small scale power generating utilities. Moreover PV systems have suitability for both off and on grid operation. Several factors affect the power output of PV panel namely intensity of solar radiation, temperature, materials used in solar panel. Literature abounds with vast amount of research articles addressing these factors. K. Daisuke et al have given comprehensive treatment on photovoltaic materials in solar cells and investigated the potential of thin film of silicon cell [9]. Y. Hamakawa et al indicated cost effectiveness of thin film solar cells [10] G. brown et al have explored the third generation photovoltaic and demonstrated its potential of combing advantages of both first and second generation photovoltaic [11]various techniques employed in third generation of solar cells viz. multifunction cells, intermediate-band cells, hot carrier cells and spectrum conversion have been analysed [12-15].

It has been observed that both fill factor and open circuit voltage of PV cell decrease with temperature while short circuit current increases [16]. Bergene et al. and Siegel et al. have explored PV array efficiency as function of temperature[17-18] E. Skoplaki et al Solar have compiled exhaustive list of correlation equations in literature dealing with operating temperature and PV array power output [19].Optimal operation of Solar photovoltaic system in a hybrid power generation system have been studied by Som. et.al [20]. The maximum output power can be 
obtained by ensuring sunlight always falls perpendicular to surface of solar panel thus having maximum intensity of solar radiation. Auto tracking mechanism is not suitable for smaller, standalone pv units having drawbacks like complex installation, operation and maintenance cost. Therefore it is imperative to evaluate optimum tilt angle for such installations.Lunde.et al and Garg et al have proposed latitude angle based methods [21-22]. These methods were simple but were prone to discrepancies.Kern et al and Hartley et al have evaluated tilt angle on basis of maximization of extra-terrestrial radiation,beam radiation and global radiation falling on the solar panel respectively. [23-24]. Various algorithms exist in literature for Maximum power point tracking (MPPT).It has been well established that selection of an appropriate MPPT Algorithm is a trade-off between True MPPT, Convergence speed and Implementation complexity [2526].

Elsayed included latitude angle and monthly average clearness index for optimal tilt angle [27].Angstrom et al.[28] have used number of sunshine hours to evaluate monthly average daily global solar radiation. However this suffers from drawback of specific area locality. Hammer et al proposed use of pixel data of the satellite image for global horizontal radiation [29]. Supit et al have introduced temperature based method for evaluation of Global radiation using the atmospheric transmittance and difference of the maximum and minimum daily temperatures [30-31].However, maximum solar power generations through optimal placement of solar angle for a specific load based area are rare in literature. Despite having number of empirical based methods for optimal tilt angle very few articled have explored heuristic methods for simultaneous operations and features of solar photovoltaic or thermal system. However, such optimized operation considering Indian context are sparse in the literature.

The present work determines maximum solar power generation through an optimal choice of the mirror tilt angle for solar panel. The choice of the tilt angles are made for collecting the most concentrated solar irradiation varying with time. The above optimization problem has been formulated for a daily load variation of a specific area in India. Further, different values of daily global and diffuse solar radiation of that particular place at India have been considered for the case study performed in the work. Modified genetic algorithm, has been developed and implemented for the above mentioned optimization problemAn electronic copy can bedownloaded from the conference website. For questions on paper guidelines, please contact the conference publicationscommittee as indicated on the conference website. Information about final paper submission is available from the conference website.

\section{PROBLEM FORMULATION}

The present work depicts the optimal power generation in consideration with optimal design for solar photovoltaic system as a decentralized or distributed power delivery system integrated with loads forming a microgrid. The optimized model for solar power distributed generating system has been developed employing a tuned form of the genetic algorithm implemented using MATLAB ${ }^{\circledR}$ considering load demand scenario for a locality in India. With regard to photovoltaic, the optimum electric power for a certain period is of economic interest. The electric power of a solar cell is defined as the product of electric current and voltage $\left(\mathrm{P}=\mathrm{I}^{*} \mathrm{~V}\right)$ that is a function of the irradiance and the temperature $P=f(I, T)$. Although $P$ increases in higher irradiances, it decreases in higher temperatures. In general, higher irradiances lead to higher temperatures of the solar collector and, hence, the performance is reduced. Furthermore, the reflection characteristics of the collector surface should be taken into account. As presented by [32], diverse surface covers behave differently according to reflection losses. Keeping all the parameters in consideration, the present work dealt with the variation of tilt angle in producing maximum power.

The real time data for outdoor performance of a standalone photovoltaic (SAPV) system in New Delhi (India) for two types of climatic loading condition have been considered. The daily power generated from the existing SAPV system was optimally generated depending on the prevailing sky conditions and the time of irradiation that reaches the earth. The number of days and daily power generated corresponding to two weather types is used to determine power generation from the existing SAPV system for loads of specific place. The objective function has considered Power generation which is dependent on many factors.

\section{A. Objective function}

Power difference between the load demand and the power generation from solar photovoltaic has been considered as the main objective function, which has to be minimized as shown in equation (1) for summer season and equation (2) for winter season

$\sum_{n=1}^{9} P_{d}=P_{1}-P_{S o}$

$\sum_{n=1}^{7} P_{d}=P_{1}-P_{S o}$

Where $\mathrm{P}_{\mathrm{d}}, \mathrm{P}_{1}$, and $\mathrm{P}_{\mathrm{So}}$ are the power difference, load demand and power generation respectively. $P_{d}$ is minimized by optimally generating solar power in correspondence to the respective load demand for different hours. The optimal power generation, i.e. $\mathrm{P}_{\mathrm{S}_{\mathrm{o}}}$ is done on the basis of design of optimal tilt angle for varying irradiance with varied time.The optimal power generation, i.e. $\mathrm{P}_{\mathrm{So}}$ is done on the basis of design of optimal tilt angle for varying irradiance with varied time.

$P_{S O}=\left[(D f)\left(R C_{P V}\right)\left(\frac{I_{T}}{S_{S}}\right)\right]$

where, $D f$ is the derating factor, $R C_{P V}$ is the rated capacity of the solar array, $I_{T}$ and $S_{S}$ are global solar radiation incident on the surface of solar array and standard solar radiation for the rated capacity. 
Generally, the total solar radiation on a horizontal surface $P l s_{\min } \leq P l s \leq P l s_{\max }$

is called global irradiance, and is the sum of incident $P l w_{\min } \leq P l w \leq P l w_{\max }$

diffuse radiation and the direct normal irradiance projected onto the horizontal surface. While, if the surface under study is tilted with respect to the horizontal, then the total irradiance is the incident diffuse radiation, and the direct normal irradiance projected onto the tilted surface, and the ground reflected irradiance that is incident on the tilted surface. Thus for a surface tilted at a slope angle from the horizontal, the incident total radiation is given by the relation [33]:

$I_{T}=I_{B}+I_{D}+I_{R}$

The solar irradiation on that particular location over defined hours for winter and summer season gives the following constraining factors as shown in equation (13) and (14);

$I_{d s \min } \leq I_{d} \leq I_{d s \max }$

$I_{d w \min } \leq I_{d} \leq I_{d w \max }$

III. NUMERICAL METHOD OF SOLUTION

Where, $I_{T}$ is the monthly average daily total radiation on a tilted surface, $I_{B}$ is normally estimated by individually considering the direct beam, and $I_{D}$ is the diffuse component and $I_{R}$ is the reflected component of the radiation on a tilted surface. The daily beam radiation received on an inclined surface can be expressed as [33]:

$I_{B}=\left(I_{g}-I_{d}\right) R_{b}$

Where, $I g$ and $I_{d}$ are the monthly mean daily global and diffuse radiation on a horizontal surface, and $R_{b}$ is the ratio of the average daily beam radiation on a tilted surface to that on a horizontal surface.The daily ground reflected radiation can be written as [33]:

$I_{R}=\left(\frac{1-\cos \beta}{2}\right) \rho I_{g}$

Where, $\beta$ is the tilt angle of the solar panel. Liu and Jordan [34] have suggested that $R_{b}$ can be estimated by assuming that it has the value which would be obtained if there were no atmosphere. For surfaces in the northern hemisphere (i.e. India, in this case study), sloped towards the equator, the equation for $R_{b}$ is given as below [34] and is used in the present study.

$R_{b}=\frac{\cos (\emptyset-\beta) \cos \delta \sin \omega_{s s}+\omega_{S S} \sin (\emptyset-\beta) \sin \delta}{\cos \emptyset \cos \delta \sin \omega_{s S}+\omega_{s S} \sin \emptyset \sin \delta}$

where $\omega_{s S}$ is sunset hour angle for tilted surface for mean day of month, $\Phi$ is latitude angle and $\delta$ is declination. The relation for sunset hour angle and declination can be expressed as [35]

$\omega_{s s}=\operatorname{Arccos}(\tan (\varnothing) \tan \delta)$

The declination of the sun is the angle between a plane perpendicular to a line between the earth and the sun and the earth's axis. The relation for declination angle is given in [14],[35].

$\delta=\frac{23.45}{180} \sin \left(\frac{2 \pi[284+n]}{365}\right)$

Where $\mathrm{n}$ is nth day of year.

The sky diffused radiation can be expressed as [12],[34]

$I_{D}=\left(\frac{1+\cos \beta}{2}\right) I_{d}$

B. Constraining function

The constraining function is the maximum and minimum load demand over a day, of a typical location in India. These ranges of load variation for both summer and winter season are mentioned in the equations (11) and (12).

The above stated algorithm considered for the solutions in the present problem has been developed. An optimal power operation of SAPV has been performed to generate maximum power through different variations of solar angle and load by the application of TGA.

\section{Input Parameters}

Temporal variations of load during a day in a small residential locality are considered. The load variations for different types of consumers in an Indian village are shown below in figure 1[42] 
INTERNATIONAL JOURNAL OF INNOVATIVE RESEARCH IN ELECTRICAL, ELECTRONICS, INSTRUMENTATION AND CONTROL ENGINEERING Vol. 3, Issue 4, April 2015

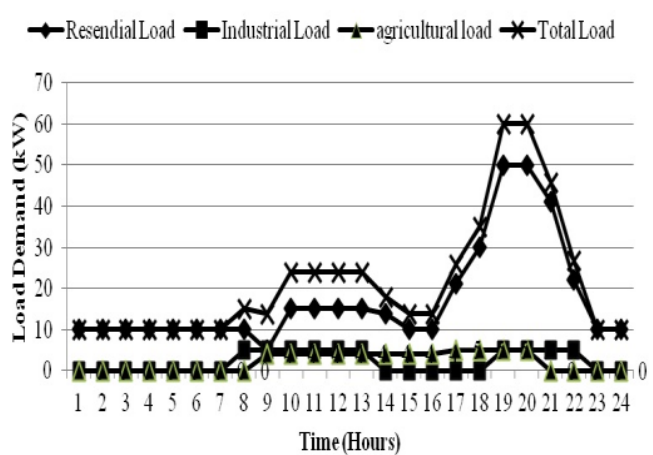

FIG.1. Four Types of Load demand in Rajmele village

The solar irradiations over a day, for summer and winter season, of the given locality in India are given in table 1 [43]

TABLE. I. Hourly Solar Irradiation in watts/metre ${ }^{2}$

\begin{tabular}{ccc}
\hline \hline Time & $\begin{array}{c}\text { Irradiation in } \\
\text { summer }\end{array}$ & $\begin{array}{c}\text { Irradiation in } \\
\text { winter }\end{array}$ \\
\hline 9.00 AM & 530 & ---- \\
10.00 AM & 680 & 620 \\
11.00 AM & 840 & 710 \\
12.00 PM & 820 & 820 \\
13.00 PM & 800 & 760 \\
14.00 PM & 700 & 530 \\
15.00 PM & 540 & 420 \\
16.00 PM & 360 & 280 \\
17.00 PM & 220 & ---- \\
\hline \hline
\end{tabular}

Different values of solar irradiation for both summer and winter season have been considered for generating power corresponding to the above mentioned consumer load.

\section{RESULTS}

In the present work, analysis of optimal operation of solar power angle has been made pertaining to minimum power deviation between the load and generation from solar photovoltaic system. Power delivery systems for two test cases have been made by the application of TGA. Optimal power distributions as computed by TGA have been analysed through maximum solar power generation.

Three types of consumers have been considered for 24 hours during both summer and winter loading condition. Three types of consumer load constitute residential, industrial and agricultural load, as shown in figure 1. The place considered for the optimal solar power generation corresponds to 9 hours and 7 hours of irradiation for summer and winter load scenario respectively.

The optimal power distribution for residential, industrial and agricultural demand during summer loading condition are shown in terms of power deviation over 9 hours in figure 2, figure 3 and figure 4 respectively. The power deviations are calculated as positive where the demand is more than the generation; while negative when the generation is more than demand. The maximum powers generated over the 9 hours, corresponding to the optimal solar angles are given in figure 5, figure 6 , and figure 7 respectively for residential, industrial and agricultural load.

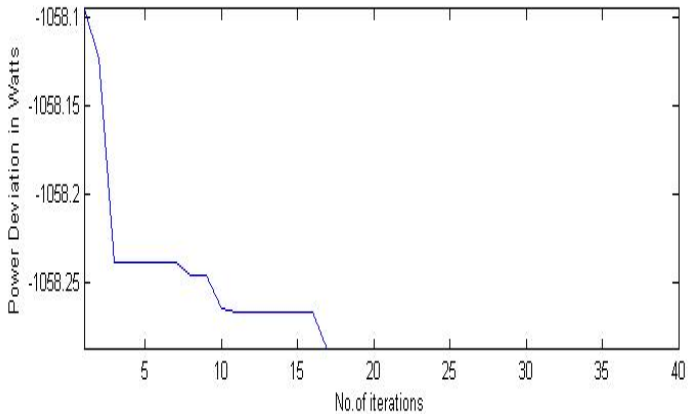

FIG.2. Power deviation for residential load in summer

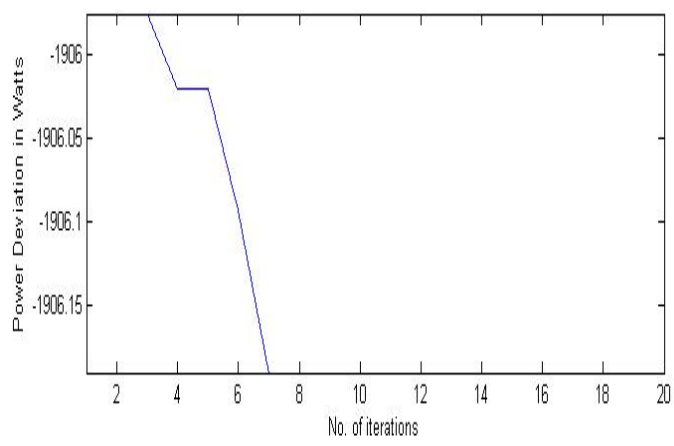

FIG.3

Power deviation for industrial load in summer

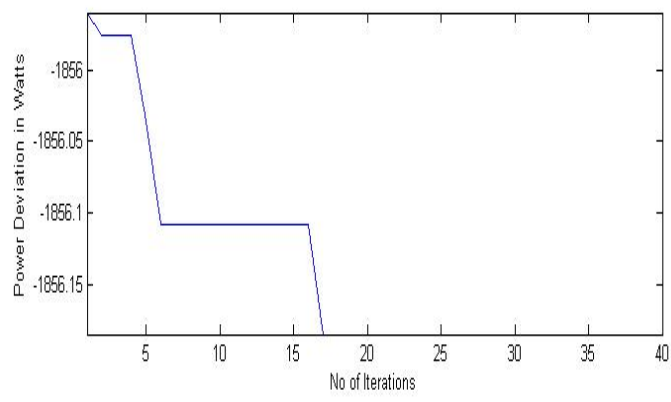

Power deviation for agricultural load in summer

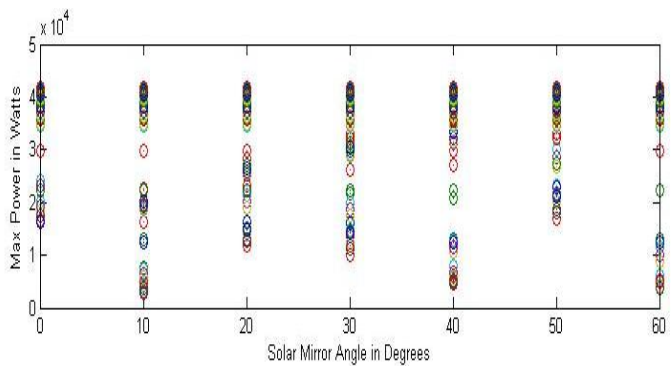

FIG.5. Maximum power generated over 9 hours for residential load in summer

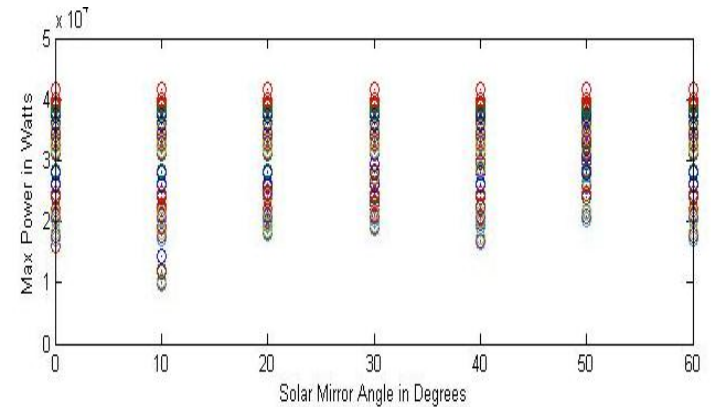

FIG 6. Maximum power generated over 9 hours for industrial load in summer 


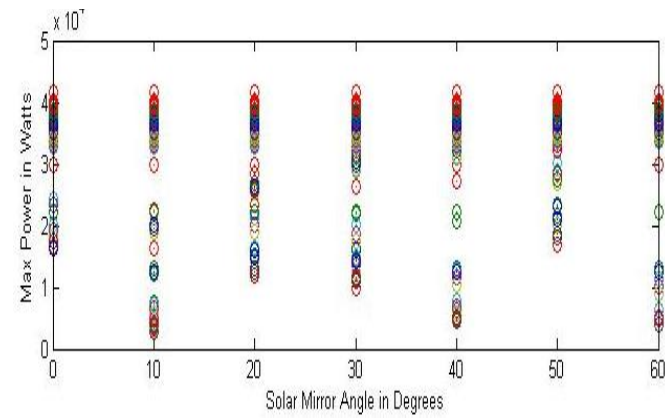

FIG.7. Maximum power generated over 9 hours for agricultural load in summer

It has been observed from figure 5, 6 and 7 that the, solar power angle achieved for maximum power generation over 9 hours are 50 degree, 60 degree and 50 degree respectively. Further, the power deviation occurred in the residential load is about $-1.052 \mathrm{~kW}$, while that in agricultural load and industrial load is about $-1.906 \mathrm{~kW}$ and $-1.856 \mathrm{~kW}$ respectively. Hence, it has been observed that for summer season for all the three loads the power deviations are negative, i.e. it can provide power for other night hours or charge some backup supply system. However, residential load delivered maximum power among three loading scenario. Similarly, the optimal power distribution for the same load considering irradiation during winters for 7 hours, has been modelled and simulated as shown below.

The optimal power distribution for residential, industrial and agricultural demand during summer loading condition are shown in terms of power deviation over 24 hours in figure 8 , figure 9 and figure 10 respectively. The power deviations are calculated as positive where the demand is more than the generation; while negative when the generation is more than demand. The maximum powers generated over the 9 hours, corresponding to the optimal solar angles are given in figure 11, figure 12, and figure 13 respectively for residential, industrial and agricultural load.

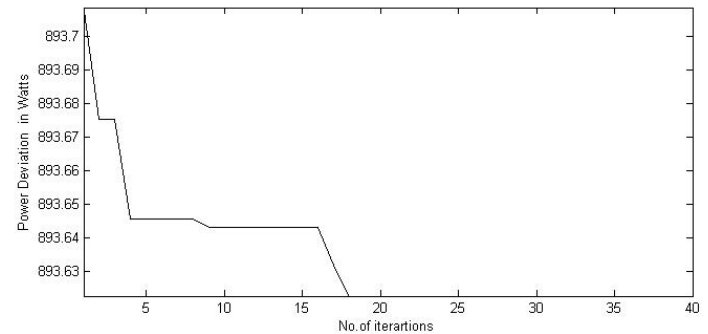

FIG.8. Power deviation for residential load in winter

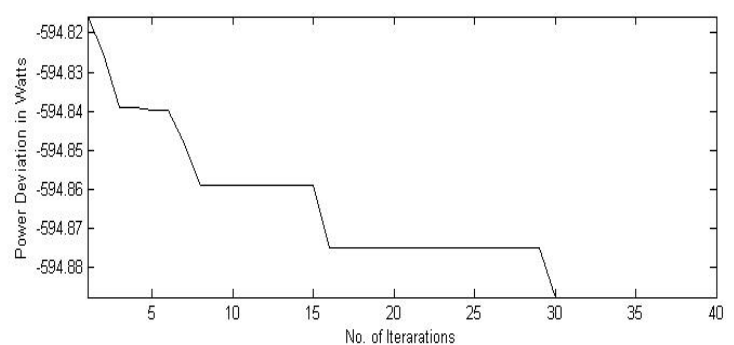

FIG.9. Power deviation for agricultural load in winter

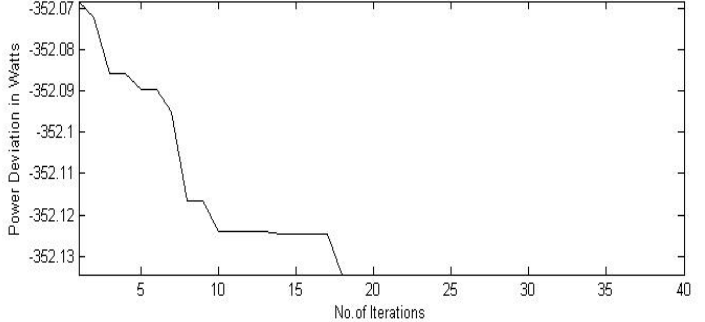

FIG.10. Power deviation for industrial load in winter

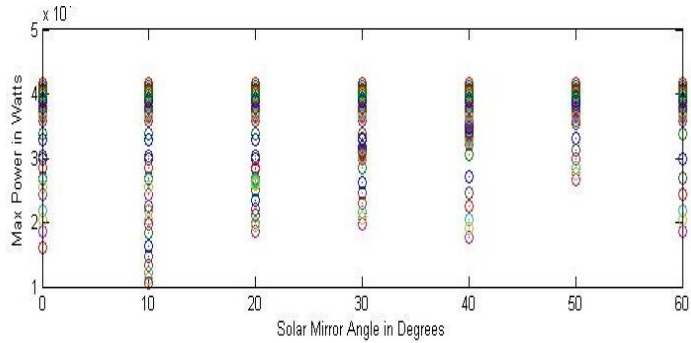

FIG.11. Maximum power generated over 7 hours for residential load in winter

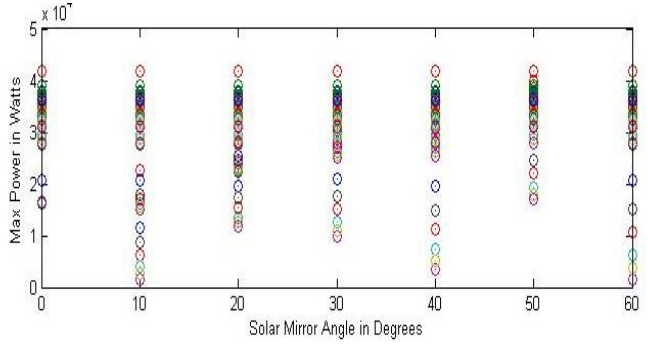

FIG.12. Maximum power generated over 7 hours for industrial load in winter

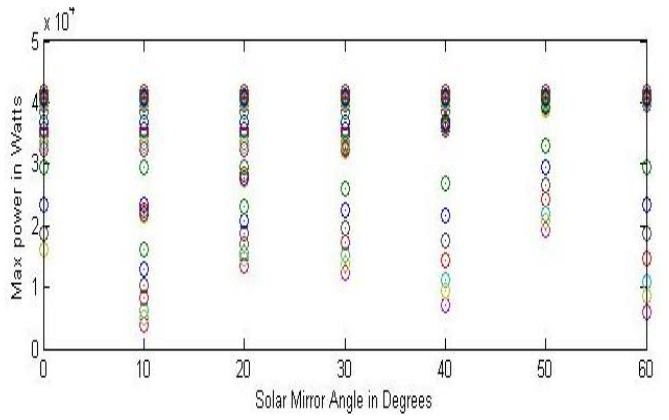

FIG.13. Maximum power generated over 7 hours for Agricultural load in winter

It has been observed from figure 11, 12 and 13 that the, mirror angle achieved for maximum power generation over 7 hours are 50 degree for all three types of loads. In winters earth receives relatively lesser amount of irradiation than in summer. The effect of lesser irradiation accounts for reduced generation in solar panel thus bringing power demand and generated output close. Further, the power deviation occurred in the residential load is about $0.8962 \mathrm{~kW}$, while that in agricultural load and industrial load is about $-0.5982 \mathrm{~kW}$ and $-0.35214 \mathrm{~kW}$ respectively. Hence, it has been observed that for winters season the power deviations is positive for residential load while for agricultural and industrial load it is negative. i.e the residential load requires battery backup supply to meet the shortfall in power generation. Moreover, these negative deviations are much lesser than those obtained in summer season. 


\section{CONCLUSION}

A mathematical simulation has been performed for optimal power generation variations in solar power angles using TGA in the context of an Indian scenario. It has been observed from the present work that, for optimal power generation corresponding to different loads have been achieved for 50 degree of solar power angle, while for residential load during summer the optimal operation occurred for 60 degree of angle. Thus it can be inferred that, with same irradiation the variation in solar power angle can produce optimal power generation. Further, the maximum negative power deviation has been obtained in the case of residential load for winter season. So, it can be concluded, that the solar photo-voltaic system during summer can provide excess power than other loads for both the summer and winter seasons which can be used for other charging battery back-up systems.

\section{REFERENCES}

[1] International Energy Outlook 2013, U.S. Energy Information Administration (EIA), July 2013

[2] MIT study on the future of the electric grid, http://web.mit.edu/mitei/research/studies/the-electric-grid2011.shtml

[3] F.Birol. "World energy prospects and challenges." Australian Economic Review.Vol 39, no 2,190-195, 2006.

[4] N.S Lewis ,GCrabtree,A.JNozik,M.RWasielewski, A.P Alivisatos. "Basic Research Needs for Solar Energy Utilization." U.S. Department of Energy: Washington, DC, 2005.

[5] ${ }^{5}$ Monthly generation report by central electrical authority, India march 2014.

[6] N. Sharma, P.K Tiwari, Y.R Sood, "Solar energy in India: Strategies, policies, perspectives and future potential" Renewable and Sustainable Energy Reviews 16 933-941 2012.

[7] R.Aringhoff, G.Brakmann and M.Geyer and S.Teske "Concentrated solar thermal power now.” Greenpeace International, 2005.

[8] http://eai.in/blog/2009/09/national-solar-mission-to-beannounced.html

[9] ${ }^{9}$ D Kanama and H. Hawamoto"Research and Development Trends of Solar Cell for Highly Efficiency."Quarterly reviewNo 28, July 2008.

[10] ${ }^{10}$ Y. Hamakawa, "Thin-Film Solar Cells: Next Generation Photovoltaics and Its Applications", (Springer, Berlin, 2004).

[11] ${ }^{11}$ Gregory F. BrownandJunqiao Wu."Third generation photovoltaics Laser \& Photon.” Rev. 3, No. 4, 394-405 lpor.200810039, 2009.

[12] ${ }^{12}$ A. Marti, L. Cuadra, and A. Luque, in: Proceedings of the 28th Photovoltaics Specialist Conference, Anchorage, AK, USA, pp. 940-943, 2000.

[13] ${ }^{13}$ A. J. Nozik, Physica E 14, 115, 2002

[14] R. T. Ross and A. J. Nozik, J. Appl. Phys. 53, 3813, 1982.

[15] T. Trupke, M. A. Green, and P. Wurfel, J. Appl. Phys. 92, 4117,2002.

[16] H.A Zondag "Flat-plate PV-thermal collectors and systems - a review." Renew. Sustain. Rnergy Rev. doi:10.1016/j.rser.2005.12.0125-5, 2007.

[17] T. Bergene., O.M Lovvik, "Model calculations on a flat-plate solar heat collector with integrated solar cells. Solar Energy 55, 453-462, 1995.

[18] M.A Siegel, S.A Klein, W.A Beckman,"A simplified method for estimating the monthly-average performance of photovoltaic systems." Solar Energy 26, 413-418, 1981.

[19] E.Skoplaki, J.A.Palyvo,"On the temperature dependence of photovoltaic module electrical performance: A review of efficiency/power correlations.”Solar Energy 83, 614-624, 2009.

[20] T. Som, N. Chakraborty, 'Studies on Economic Feasibility of an Autonomous Power Delivery System Utilizing Alternative Hybrid Distributed Energy Resources', IEEE Transactions on Power Systems, Volume 27, Issue 1, 172-181,January 2014.

[21] P.J Lunde. Solar thermal engineering: space heating and hot water systems (New York, John Wiley \& Sons, 1980)
[22] H.P GargTreatise on solar energy. In Fundamentals of solar energy, vol. I. (New York, John Wiley \& Sons, 1982)

23] J. Kern and I. Harris. "On the optimum tilt of a solar collector." Sol Energy 17:97-102, 1975 .

[24] L.E Hartley and J.A Martinez-Lozano. 'The optimization of the angle of inclination of a solar collector to maximize the incident solar radiation' Renew Energy 17:291-309, 1999.

[25] T. Esramand P. L. Chapman, "Comparison of Photovoltaic ArrayMaximum Power Point Tracking Techniques," IEEE transactions onenergy conversion, vol. 22, no. 2, June 2007.

[26] M. Berrera, A. Dolara, R. Faranda, and S. Leva, "Experimental test ofseven widely-adopted MPPT algorithm," IEEE Bucharest Power TechConference, 1-8, 2009

27] R.Perez ,P.Ineichen, R.Seals, J. Michalsky and R. Stewart "Modeling daylight availability and irradiance components from direct and global irradiance." Sol Energy 44:271-89, 1990.

[28] A. Angstrom. "Solar and terrestrial radiation." QJR Met Soc 1924; 50:121-5

[29] A.Hammer, D.Heinemann, C. Hoyer, R. Kuhlemann, E. Lorenz and H.G Muller. "Solar energy assessment using remote sensing technologies." Remote Sens Environ 86:423-32, 2003.

[30] G.L Hargreaves and G.H Hargreaves. "Irrigation water requirement for the Senegal River basin.”Jidedh111(3):265-75, 1985.

[31] I.Supit and Van Kappel "A simple method to estimate global radiation.” Sol Energy 63(3):147-60, 1998.

[32] S.Beringer, et al. "Case study showing that the tilt angle of photovoltaic plants is nearly irrelevant." Solar energy $85.3470-476$, 2011

[33] M. Benghanem, "Optimization of tilt angle for solar panel: case study for Medina, Saudi Arabia." Applied Energy 88.4 1427-1433, 2011 .

[34] B.Liu B and R.Jordan. "Daily insolation on surfaces tilted towards the equator." Trans ASHRAE 67, 1962.

[35] Sharma, Rakhi, and G. N. Tiwari. "Life cycle assessment of standalone photovoltaic (SAPV) system under on-field conditions of New Delhi, India." Energy Policy63272-282,2013.

[36] E.Goldberg, Hand book of Genetic Algorithms in Search, Optimization and Machine Learning. (Boston, Addison-Wesley, 1989)

[37] D.K Pratihar,Soft Computing.(Beijing, Science Press, 2009)

[38] A.Wright. "Genetic Algorithms for Real Parameter Optimization." In: Rawlins G J E, ed. Foundations of Genetic Algorithms I. London: Morgan Kaufmann, 205-218,1991.

[39] L.J Eshelman and J.D Schaffer. "Real-coded genetic algorithms and interval schemata." Whitley D, ed. Foundation of Genetic Algorithms II. London: Morgan Kaufmann, 1993, 187-202

[40] J. Baker in Adaptive selection methods for genetic algorithms 1985: Proceedings of International Conference on Genetic Algorithms and their Applications. Scottsdale, 1985 edited by J.J Grefenstette(Psychology Press 1985) pp. 101-111.

[41] K.Deb and M.A Goyal. "A combined genetic adaptive search for engineering design." Journal of Computer Science and Informatics, 26(4): 30-45, 1996

[42] Banerjee and Rangan in Electricity demand estimation for village electrification 2000: Proceedings of National Renewable Energy Conference, IIT Bombay, India, Nov2000.

43] Chel, Arvind, and G. N. Tiwari,"A case study of a typical $2.32 \mathrm{~kW}$ stand-alone photovoltaic (SAPV) in composite climate of New Delhi, India." Applied Energy 88.4 1415-1426,2011.

\section{BIOGRAPHIES}

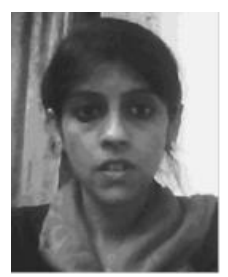

Trina Som was born in Kharagpur, India, on October 8, 1982. She received her M.S. degree in Power engineering in 2008 and her $\mathrm{PhD}$ degree in 2013 from Jadavpur University, Kolkata, India. At present, she is Assistant Professor in Department of Electrical Engineering at JSSATEN, UPTech University Noida, India. Her Research areas include Economical and operational viability of Renewable energy,Power systems, Soft computing techniques and Optimization algorithms. 
INTERNATIONAL JOURNAL OF INNOVATIVE RESEARCH IN ELECTRICAL, ELECTRONICS, INSTRUMENTATION AND CONTROL ENGINEERING Vol. 3, Issue 4, April 2015

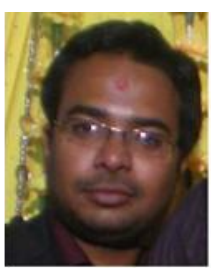

Rahul Pathak was born in Varanasi, India, on 11 September 1985.India.He received his B.E degree in electrical engineering in 2007 and M.E degree in control system in 2010 from B.I.T Mesra, Ranchi, India. At present he is Assistant Professor in Department of Electrical \& Electronics Engineering at N.I.E.C, Indrapastha University, New Delhi, India. His area of interest includes Renewable Energy, Soft Computing Techniques and System Biology. He can be mailed at: mailrahulpathak@gmail.com 